\title{
Effects of Carbon Black Content on Cure Characteristics, Mechanical Properties and Swelling Behaviour of 80/20 NBR/CIIR Blend
}

\author{
I. S. Saad", M. Sh. Fayed ${ }^{* *}$, and E. M. Abdel-Bary ${ }^{* * *}$
}

\begin{abstract}
The influences of carbon black loading on rheological and mechanical properties were investigated for 80/20 NBR/CIIR blend vulcanized with a semi-efficient system. The swelling behaviour of the vulcanizates in six different solvents was studied as well. Carbon black (type N347) was used as filler and the loading range was from 40 to 100 phr. Results showed that cure rate index, hardness, tensile strength and stress at 100\% elongation increase with increasing carbon black loading while scorch time, cure time, elongation at break and resilience decrease. It was also found that the solvent uptake decrease linearly with increasing carbon black loading.
\end{abstract}

Keywords: NBR / CIIR blend, cure characteristics, mechanical properties, swelling behaviour, carbon black loading

\section{Introduction}

Rubber must be reinforced with carbon black for most applications to improve the end-use performance associated with the increased modulus, abrasion resistance and ultimate properties (tear and tensile strength). The carbon blacks affect strongly the physical properties of rubber depending on the loading level, particle size, structure of aggregated particles, and the physico-chemical properties of its particles.

There has been an extensive study on the carbon black reinforcement of rubber [1-15]. The carbon blacks physically adsorb rubber molecules to their surfaces [5,6] or occlude them in internal voids [7] which results in a partial immobilization of the rubber and an apparent increase in filler volume. They also form an agglomerated inter-particular structure [5-8] which may be associated with specific elastic properties and a continuous breakup and rearrangement, finally leading to a strong nonlinear viscoelastic behavior $[6,8]$.

\footnotetext{
* Egyptian Armed Forces, Ibrahim_mtc@yahoo.com

** Egyptian Armed Forces.

**** Mansoura University, Mansoura, sbarys@yahoo.com
} 


\section{Experimental}

\subsection{Materials}

The basic materials used are: nitrile rubber (N3980, Mooney viscosity $\left[\mathrm{ML}(1+4) 100^{\circ} \mathrm{C}\right]$ : $80 \pm 5$, bound acrylonitrile 34 \pm 1 , Enichem. Chemical Co.), chlorobutyl rubber (Exxon 1066, Mooney viscosity $\left[\mathrm{ML}(1+4) 100^{\circ} \mathrm{C}\right]: 55 \pm 3$, chlorine content 1.2, Exxon Chemical Co.), zinc oxide (ZnO, Bayer, Germany), magnesium oxide (MgO, Bayer, Germany), sulphur (S, Dammam, KSA), tetramethylthiuram disulphide (TMTD, Bayer, Germany), dibenzothiazyl disulphide (MBTS, Bayer, Germany), high abrasion furnace black (HAF type N347, Degussa, Germany), antioxidant (ZA 4010, Bayer, Germany),.and dibutyl phthalate (DBP, Bayer, Germany).

\subsection{Recipes}

The compositions of the mixes are as per formulations given in table (1). All quantities are expressed in phr (parts per hundred parts of rubber).

Table (1) Compounding recipes of the mixes

\begin{tabular}{l||c|c|c|c}
\hline \hline \multicolumn{1}{c||}{ Ingredient } & Mix 1 & Mix 2 & Mix 3 & Mix 4 \\
\hline \hline Nitrile rubber & 80 & 80 & 80 & 80 \\
\hline Chlorobutyl rubber & 20 & 20 & 20 & 20 \\
\hline ZnO & 5.0 & 5.0 & 5.0 & 5.0 \\
\hline MgO & 0.4 & 0.4 & 0.4 & 0.4 \\
\hline Stearic acid & 1.0 & 1.0 & 1.0 & 1.0 \\
\hline A.O.(ZA 4010) & 1.0 & 1.0 & 1.0 & 1.0 \\
\hline DBP & 10 & 10 & 10 & 10 \\
\hline HAF & 40 & 60 & 80 & 100 \\
\hline MBTS & 2.0 & 2.0 & 2.0 & 2.0 \\
\hline TMTD & 0.5 & 0.5 & 0.5 & 0.5 \\
\hline S & 1.5 & 1.5 & 1.5 & 1.5 \\
\hline \hline
\end{tabular}

\subsection{Techniques and methods}

\subsubsection{Mixing and compounding}

Mixing was performed according to ASTM D-3182 on a laboratory open two-roll mill (400 $\mathrm{mm}$ diameter and $600 \mathrm{~mm}$ working length). The gear friction of the mill is 1:1.4. The hollow rolls were cooled by using flushing water in order to regulate the temperature not exceeding $60{ }^{\circ} \mathrm{C}$ during the different stages of mixing. The rubber mixes obtained were sheeted and left for a period of at least $6 \mathrm{hrs}$ before testing. The addition of ingredients during mixing was carried following the same order and conditions of mixing.

\subsubsection{Cure assessment}

The cure characteristics of rubber compounds were investigated using an Oscillating Disc Rheometer (ODR) model 4308 from Zwick, Germany. The measured parameters are:

$M_{L}$ : Minimum torque (N.m),

$M_{H}$ : Maximum torque (N.m),

$t_{\mathrm{s} 2}$ : Scorch time (min), 
$M_{c 90}$ : Torque at $90 \%$ of full torque development (N.m), where:

$$
M_{c 90}=M_{L}+\left[\left(M_{H}-M_{L}\right) * 0.9\right]
$$

$\mathrm{t}_{c 90}$ : optimum cure time (min),

and CRI: Cure rate index $\left(\mathrm{min}^{-1}\right)$ given by:

$$
C R I=\frac{100}{t_{c 90}-t_{s 2}}
$$

These measurements were performed according to ASTM D-2084.

\subsubsection{Curing (Vulcanization):}

The rubber mixes were compression-moulded at $150 \pm 2{ }^{\circ} \mathrm{C}$, using an electrically-heated hydraulic press (Atsfaar, Italy) to their optimum cure times derived from rheological measurements.

\subsubsection{Physico-mechanical properties of the test samples}

- Mechanical properties

Dumb-bell shaped specimens were punched from the compression-moulded sheets using Ctype dumb-bell stamp with the aid of a laboratory pneumatic cutter (model SE-Series Laboratory Sized Swing Arm Clicker Press, Canada). The tensile test was done as per ASTM D-412 by tensile testing machine model 1445 from Zwick, Germany at a separation speed of $500 \pm 10 \mathrm{~mm} / \mathrm{min}$.

- Resilience

Rebound resilience was measured using vertical rebound (Digi Test-resilience-elasticity tester, Canada) in accordance with ASTM D-1054.

- Hardness

Shore A type durometer (Digi-Test modular automatic measuring system, Canada) was employed to measure the hardness of the vulacanizates. The method adopted is as that of the ASTM D-2240 and the readings was taken after 5 seconds indentation.

All tests were carried out at room temperature $\left(25 \pm 2{ }^{\circ} \mathrm{C}\right)$.

\subsubsection{Swelling of the test samples}

The experiments were carried out according to ASTM D-471. The swelling was performed by immersing the specimens in air-tight, metal-capped test bottles filled with six different solvents, which kept at a constant temperature of $25 \pm 2{ }^{\circ} \mathrm{C}$ in a temperature-controlled air oven. The samples were periodically removed from the test bottles, the adhering solvent blotted off the surface and the samples were weighed and immediately replaced into the test bottle. This procedure was continued until equilibrium swelling was attained. The equilibrium swelling (solvent uptake) was expressed as weight percent of the original sample weight according to the following equation:

$$
\text { Equilibrium swelling } \%=\left[\left(W-W_{o}\right) / W_{o}\right] * 100
$$

where $W_{o}$ is the initial unswollen mass and $W$ is the mass after equilibrium swelling. 


\section{Results and Discussion}

\subsection{Effect of carbon black loading on rheological properties}

The minimum and maximum torque, $M_{L}$ and $M_{H}$, and the difference $\Delta M\left(=M_{H}-M_{L}\right)$, increase with increasing the carbon black content. The increase in $M_{L}$ is in line with the wellknown behaviour of viscosity increase with the addition of carbon black. $\Delta M$ is generally related to the degree of cross-linking and hence its increase can be attributed to the increase of the cross-link density. The scorch time decrease is due to the restriction of the mobility and deformability of the matrix with the introduction of mechanical restraints. The cure rate index increase results from the basicity of the carbon black, which accelerates the vulcanization reaction. The effects of carbon black loading on rheological properties are shown in table (2)

Table (2) Effects of filler loading on rheological properties

\begin{tabular}{l|c|c|c|c}
\hline \hline \multicolumn{1}{c||}{ Carbon loading (phr) } & 40 & 60 & 80 & 100 \\
\hline \hline $\mathbf{M}_{\mathbf{L}}(\mathrm{N} . \mathrm{m})$ & 0.8 & 1.1 & 1.5 & 2.5 \\
\hline $\mathbf{M}_{\mathbf{H}}(\mathrm{N} . \mathrm{m})$ & 4.3 & 5.2 & 6.6 & 8.1 \\
\hline $\mathrm{T}_{s 2}(\mathrm{~min})$ & 1.6 & 1.4 & 1.2 & 1.0 \\
\hline $\mathrm{T}_{c 90}(\mathrm{~min})$ & 10.5 & 8.9 & 7.4 & 6.5 \\
\hline CRI $\left(\mathrm{min}^{-1}\right)$ & 11.1 & 14.4 & 16.2 & 18.1 \\
\hline \hline
\end{tabular}

\subsection{Effect of carbon black loading on physico-mechanical properties}

As carbon content increases, the rubber - filler interactions increase which cause the increase of hardness, tensile strength and stress at 100\% elongation (M100). The decrease in resilience is due to the restriction of the chains mobility resulting from the physical cross-links introduced by the filler. The drop in elongation at break is because of the decrease of the rubber content in the matrix as more filler is introduced.

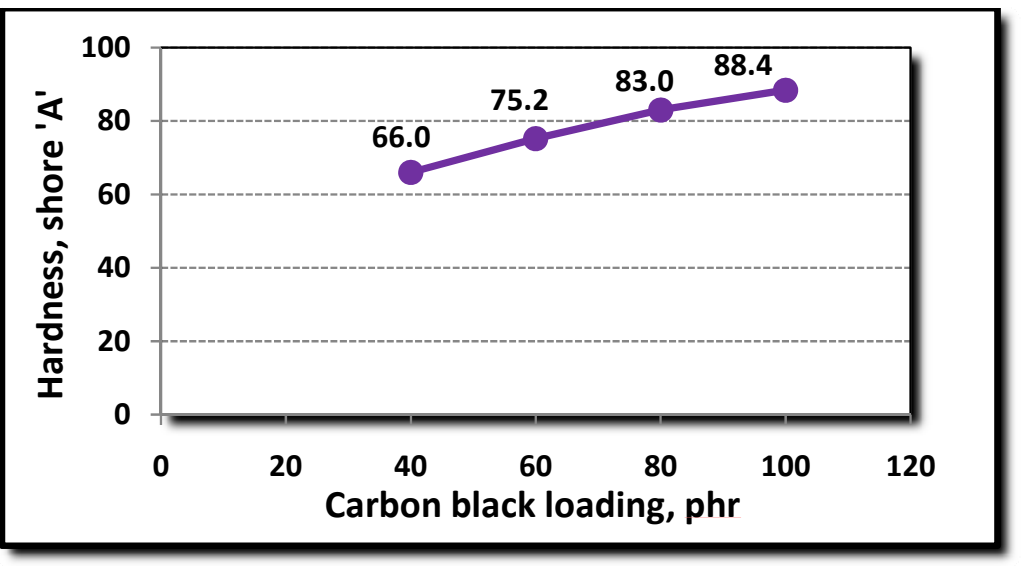

Fig. (1) Effect of filler loading on hardness. 


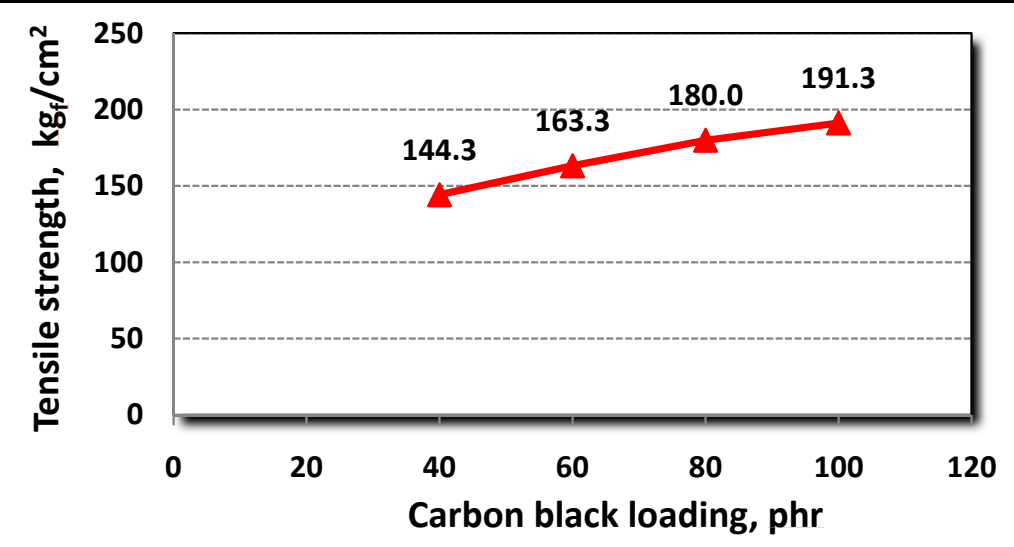

Fig. (2) Effect of filler loading on tensile strength.

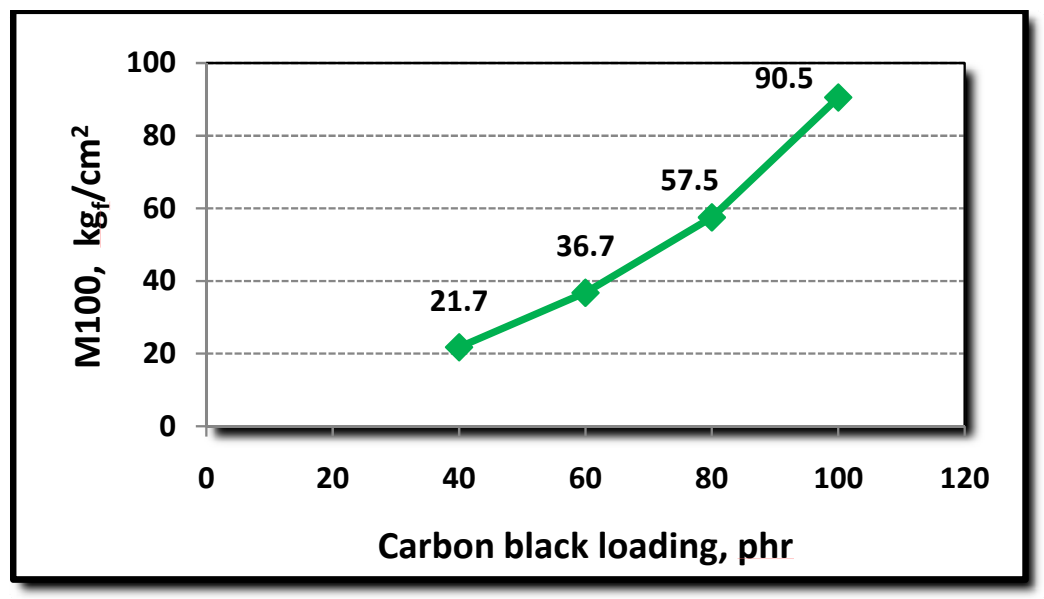

Fig. (3) Effect of filler loading on M100.

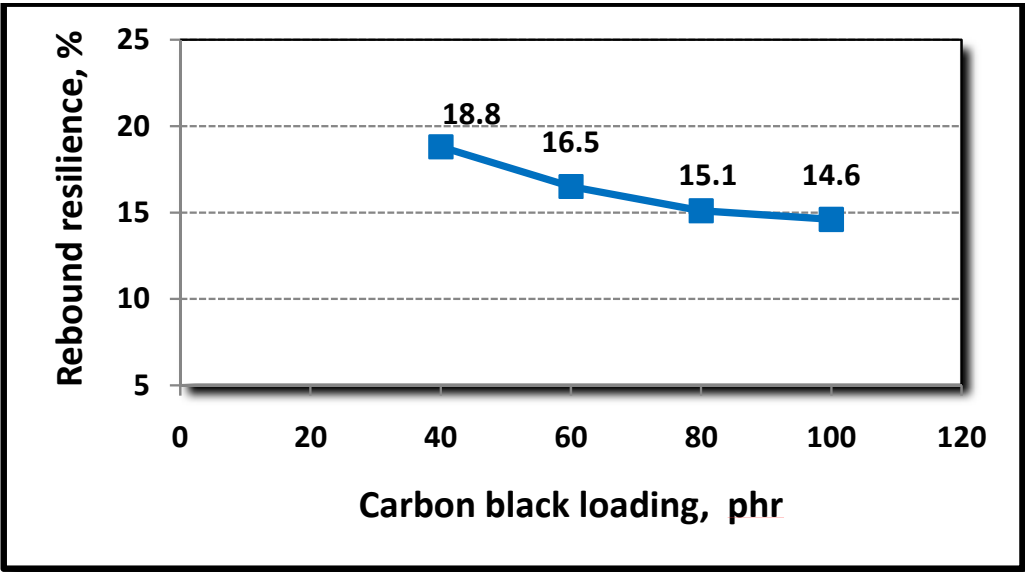

Fig. (4) Effect of filler loading on resilience. 


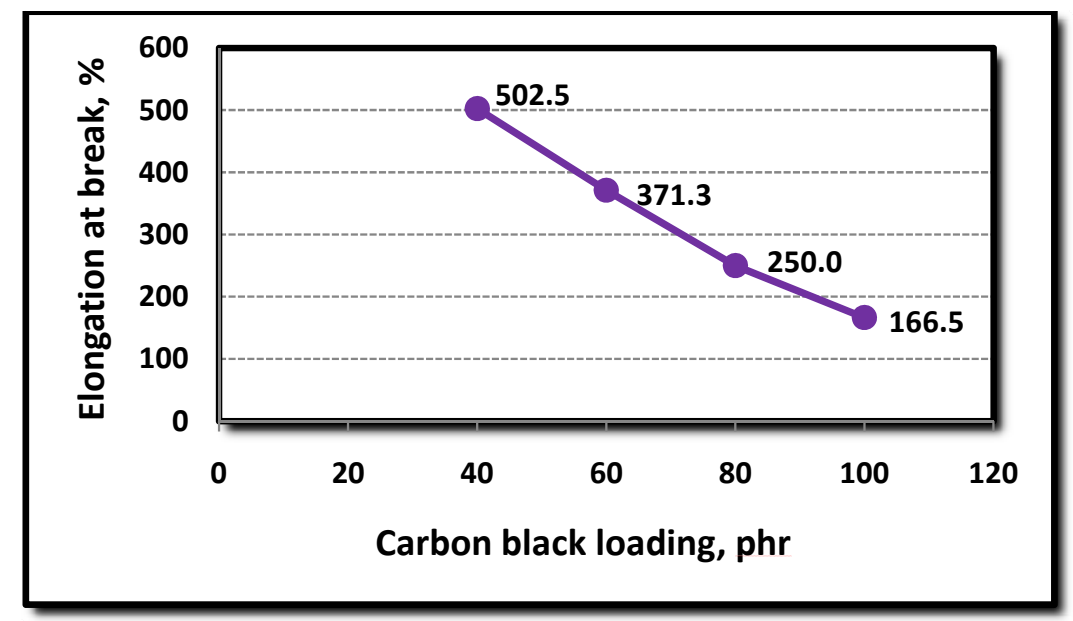

Fig. (5) Effect of filler loading on elongation at break.

\subsection{Effects of carbon black loading on swelling behaviour}

The solvent uptake decreases linearly with increasing carbon black loading and the effect is more pronounced with the highly swelling solvents (chloroform and 1,4-dioxane) which possess the highest slopes (as observed in figures 6-11). This is again because of the introduction of physical cross-links which restrict the swelling of the rubber. Maximum swelling occurs with chloroform and 1,4-dioxane because of the rubber blend has solubility parameter value close to the solubility parameter of these solvents. The main physical properties of the used solvent are given in table (3).

Table (3) Physical properties of solvents

\begin{tabular}{l|c|c|c|c}
\hline \hline \multicolumn{1}{c|}{ Solvent } & $\begin{array}{c}\text { Molecular wt. } \\
(\mathrm{g} / \mathrm{mol})\end{array}$ & $\begin{array}{c}\text { Density } \\
(\mathrm{g} / \mathrm{ml})\end{array}$ & $\begin{array}{c}\text { Molar volume } \\
(\mathrm{ml} / \mathrm{mol})\end{array}$ & $\begin{array}{c}\text { Solubility parameter } \\
\left(\mathrm{cal}^{1 / 2} \cdot \mathrm{cm}^{-3 / 2}\right)\end{array}$ \\
\hline \hline n- hexane & 86.17 & 0.660 & 130.57 & 7.3 \\
\hline butyl acetate & 116.16 & 0.804 & 144.47 & 8.3 \\
\hline chloroform & 119.38 & 1.366 & 87.39 & 9.3 \\
\hline 1,4-dioxane & 88.11 & 0.981 & 89.81 & 10.0 \\
\hline cyclohexanol & 100.16 & 0.940 & 106.55 & 11.4 \\
\hline propylene glycol & 76.09 & 1.035 & 73.52 & 12.6 \\
\hline \hline
\end{tabular}




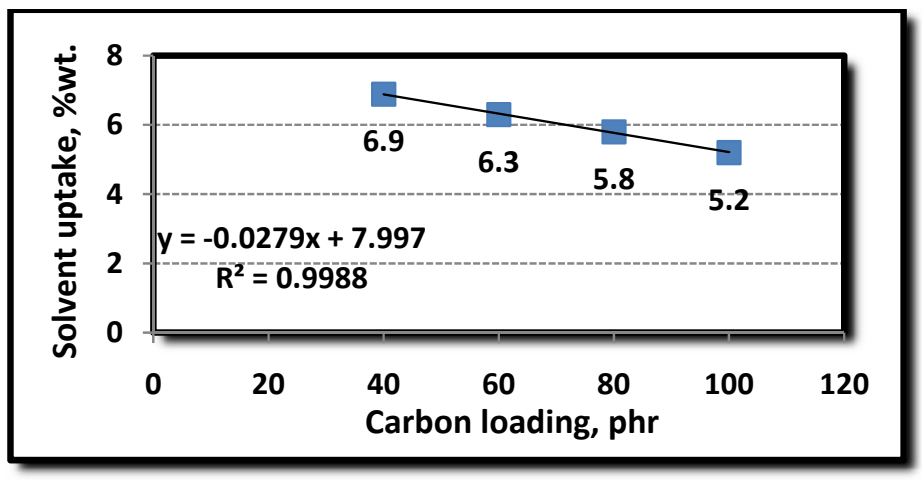

Fig. (6) Effect of filler loading on blend swelling in n-hexane.

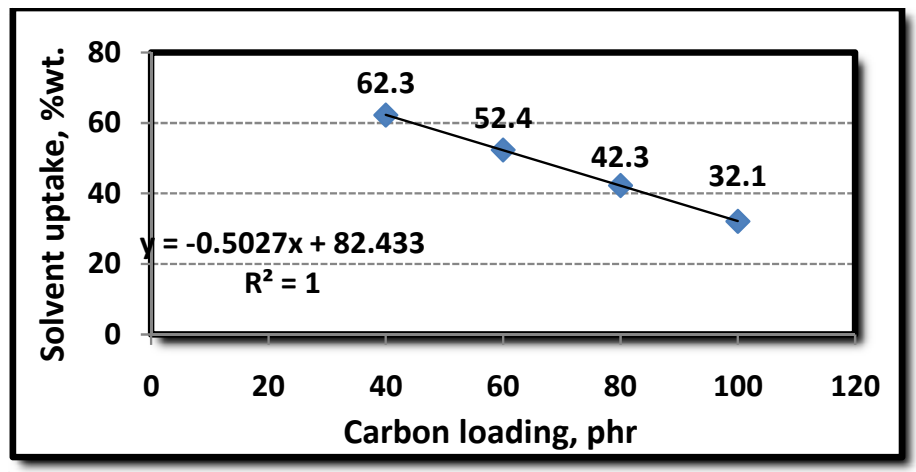

Fig. (7) Effect of filler loading on blend swelling in butyl acetate.

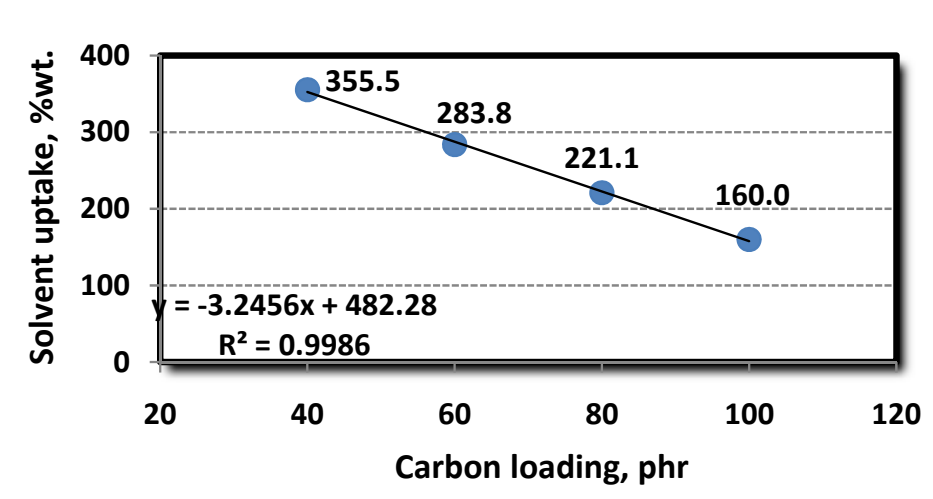

Fig. (8) Effect of filler loading on blend swelling in chloroform. 


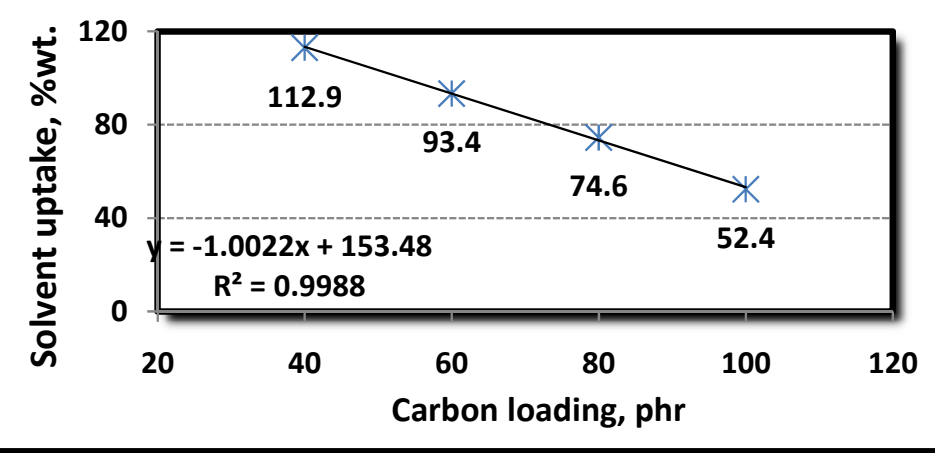

Fig. (9) Effect of filler loading on blend swelling in 1,4-dioxane.

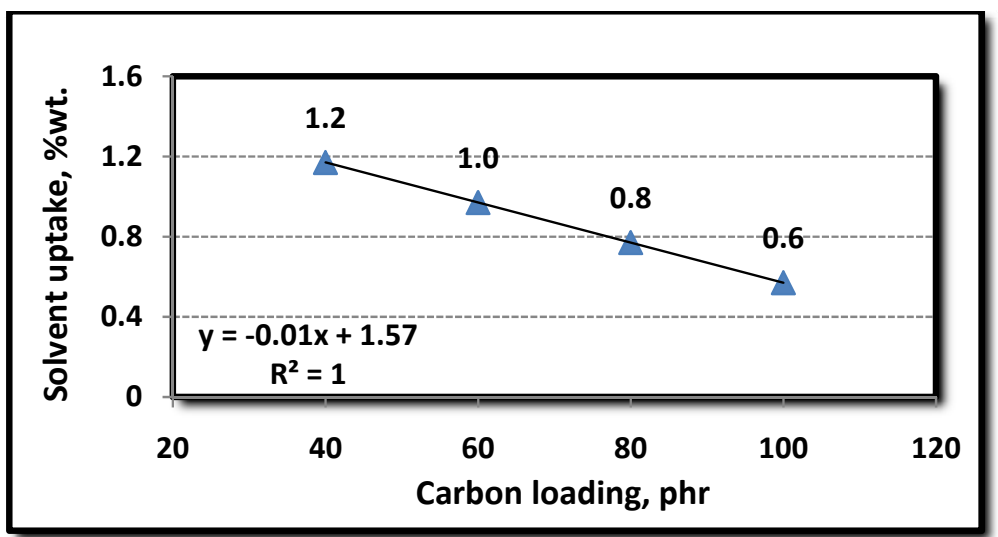

Fig. (10) Effect of filler loading on blend swelling in propylene glycol.

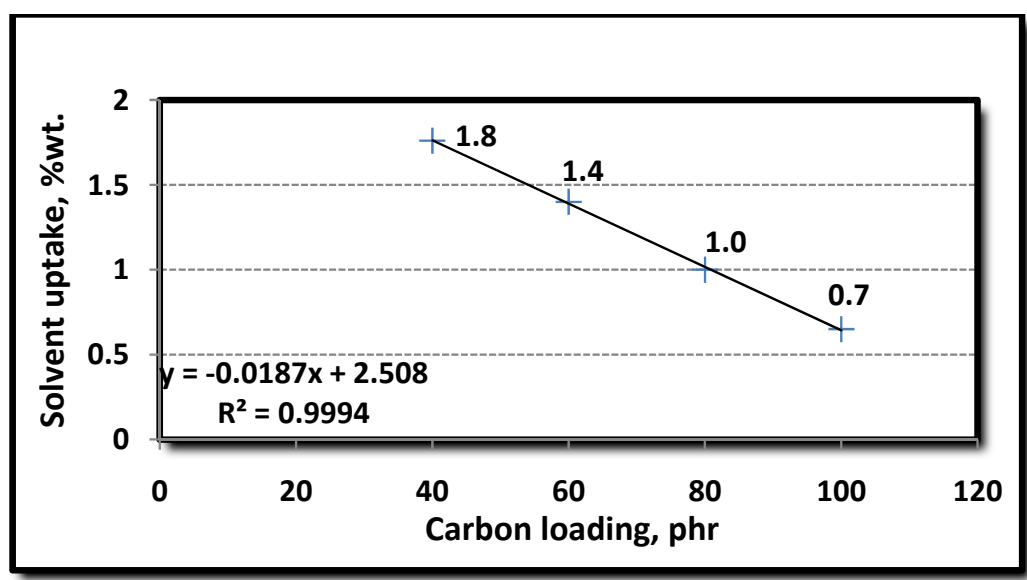

Fig. (11) Effect of filler loading on blend swelling in cyclohexanol. 


\section{Conclusions:}

The minimum and maximum torque, and the difference between them increased considerably with increasing carbon black loading. The scorch time and the cure time decreased with increasing carbon black loading while the cure rate index increased.

The hardness, stress at $100 \%$ elongation and tensile strength increased with increasing carbon black loading while resilience and elongation at break decreased. The solvent uptake decreased linearly with increasing carbon black loading and the effect was more noticeable in the highly swelling solvents.

\section{References}

[1] E.M. Dannenberg, Rubber Chem. Technol., 59, 512 (1986).

[2] D.R. Lioyd and V. Nanasimhan, J. Liq. Chron., 3, 111 (1980).

[3] J. B. Donnet and A. Vidal, Adv. Polym. Sci., 76, 103 (1986).

[4] A. R. Payne, J. Appl. Polym. Sci., 9,2273(1965).

[5] S. Wolff, M. J. Wang, and E. H. Tan, Rubber Chem. Technol., 66, 163 (1993).

[6] A. Y. Malkin, Adv. Polym. Sci., 96, 69(1990).

[7] A. I. Medalia, Rubber Chem. Technol., 51, 437(1978).

[8] C. M. Roland and G. F. Lee, Rubber Chem. Technol., 63, 554 (1996).

[9] H. Eggers and P. Schummer, Rubber Chem. Technol., 69, 253 (1996).

[10] A. I. Medalia, Rubber Chem. Technol., 46, 877 (1973).

[11] Gerard Kraus, Rubber Chem. Technol., 44, 199 (1971).

[12] M. Porter, Rubber Chem. Technol., 40, 866 (1967).

[13] P. L. Cho and G. R. Hamed, Rubber Chem.. Technol., 65, 475 (1992).

[14] Ronald J. Schaefer, Rubber World, 16 (1995).

[15] G. R. Hamed and S. Hatfield, Rubber Chem. Technol., 62, 143 (1989). 